Artículos

\title{
La construcción del inmigrante en el discurso político argentino: el caso del Parque Indoamericano
}

The construction of the immigrant in the Argentine political discourse: the case of Parque Indoamericano A construção do imigrante no discurso político argentino: o caso do Parque Indo-americano

Rocío Flax ${ }^{1,2}$

\section{RESUMEN}

El presente trabajo se inscribe en una investigación que analiza las representaciones construidas sobre los inmigrantes en el discurso político y legislativo argentinos. En esta ocasión, nos proponemos a analizar el tratamiento que se realiza sobre los inmigrantes en Argentina en una coyuntura particular: la toma del Parque Indoamericano en el año 2010. Para eso, analizaremos discursos públicos del entonces jefe de gobierno, Mauricio Macri, y de la entonces presidenta, Cristina Fernández. Utilizamos la teoría de los marcos conceptuales de Lakoff $(2002,2010)$ para observar de qué manera cada político clasifica a los inmigrantes y con quéfenómenos sociales o naturales los conectan. Veremos que, si bien los políticos valoran a los inmigrantes de maneras diferentes y plantean actitudes distintas hacia el fenómeno de la inmigración, en ambos casos

1. Doctora en Lingüística. Facultad de Filosofía y Letras, Universidad de Buenos Aires, Argentina. https://orcid.org/0000-0003-4892-0925. E-mail: rocioflax@educ.ar.

2. Docente Auxiliar, Ciclo Básico Común, Universidad de Buenos Aires, Argentina. 
Rocío Flax

subyacen las mismas conexiones entre inmigración y otros conceptos, es decir, las mismas representaciones sociales sobre la inmigración.

Palabras-clave: Inmigración; Framing; Representaciones sociales; Sentido común.

\section{ABSTRACT}

The following paper is part of a comprehensive research project on social representations about immigrants in the political and legislative discourses in Argentina. In this case, we will focus on the treatment of immigrants in the political discourse with reference to a particular situation: the occupation of Parque Indoamericano in 2010. For this purpose, we will consider public speeches delivered by former Buenos Aires city Major Mauricio Macri and former President Cristina Fernández. We will adopt the Framing theory (Lakoff, 1987, 2002, 2010) in order analyse the way the two of them classify immigrants, and to what social or natural phenomena they are linked. We will notice that, although both politicians value immigration differently and have different attitudes towards that phenomenon, in either case, the same connections are established, i.e. the same social representations appear associated to immigration.

Keywords: Immigration; Framing; Social Representations; Common Sense.

\section{RESUMO}

O presente trabalho é parte de uma pesquisa que analisa as representações construidas relativas aos imigrantes no discurso político e legislativo da Argentina. Nesta ocasião, analisamos o tratamento realizado sobre os imigrantes no discurso político argentino em uma conjuntura em particular: a ocupação do Parque Indoamericano no ano 2010. Para tal, iremos analisar discursos públicos do então Chefe de Governo Mauricio Macri e a então presidente Cristina Fernández. Utilizamos a teoria dos marcos conceituais (LAKOFF, 2002; 2010) para observar como cada político qualifica aos imigrantes e com que fenômenos sociais ou naturais são por eles conectados. Assim veremos que, embora os dois políticos valorem aos imigrantes de formas diferentes e representem diferentes atitudes em relação ao fenômeno da imigração, em ambos os casos são dissimuladas as mesmas conexões entre imigração e outros conceitos, ou seja, as mesmas representações sociais sobre a imigração.

Palavras-chave: Imigração; Enquadramento; Representações Sociais; Senso comum. 


\section{Introducción}

En Argentina, habitan - de acuerdo con el censo del año 2010 (INDEC, 2010) - 1.805.957 inmigrantes, que representan 4,5\% de la población del país. Esto supone un porcentaje mayor que el promedio global: $3 \%$ de la población del mundo no vive en su país de nacimiento (BAIADERA, 2012). Por su parte, 1.245.054 de los habitantes extranjeros provienen de países limítrofes, en particular de Paraguay y Bolivia.

Las políticas migratorias han fluctuado a lo largo de los diferentes períodos históricos de acuerdo con los proyectos políticos y económicos de la clase dirigente (TORRES, 2013; MELELLA, 2015). Los estudios sobre inmigración provenientes de la sociología y las ciencias políticas han analizado los sucesivos marcos normativos, que reflejan las diferentes actitudes políticas con respecto a los extranjeros. De esta manera, la Ley Avellaneda ${ }^{3}$, sancionada en 1876, enunció los derechos y beneficios de los inmigrantes - tales como alojamiento, manutención y traslados dentro del país - y creó oficinas de empleo para ubicarlos laboralmente y asegurarse de que los empleadores no abusaran de ellos. Además, creó y organizó un sistema de agentes y comisiones de inmigración en el exterior cuyo fin era difundir los beneficios de migrar hacia Argentina (NOVICK, 2008; TORRES, 2013; MELELLA, 2015). En cambio, pocos años más tarde, las Leyes de Residencia (1902) y de Defensa Social (1910) posibilitaron la deportación sin juicio previo de cualquier extranjero que cuestionase o perturbase el orden político y las ideas vigentes, y prohibieron la entrada al país de los anarquistas y demás personas que preconizasen el ataque contra las instituciones (CESANO, MUÑOZ, 2010; DOMENECH, 2015).

La Ley Avellaneda fue recién reemplazada en el año 1981, durante la última dictadura cívico-militar establecida por la Ley General de Migraciones y Fomento de la Inmigración N..$^{\circ} 23.439$, también conocida como Ley Videla ${ }^{4}$. La nueva normativa se vio sustentada por la Doctrina

3. La ley lleva el nombre del entonces presidente Nicolás Avellaneda, quien gobernó la República Argentina entre los años 1874 y 1880.

4. Jorge Rafael Videla fue un dictador, designado presidente de facto de la República Argentina entre 1976 y 1981 por la junta militar que había encabezado el Golpe de Estado del año 1976. 
de Seguridad Nacional y consideró el fenómeno migratorio desde una óptica casi exclusivamente policial (OTEIZA; NOVICK; ARUJ, 1997). $\mathrm{Su}$ texto no solo vulneró la Constitución Nacional de la República Argentina, sino los tratados internacionales de derechos humanos. Es decir, restringió el acceso a la salud, educación y el trabajo a los inmigrantes en situación irregular; limitó las posibilidades de realizar trámites de radicación a los extranjeros que deseasen hacerlo una vez instalados en el país; redujo a su mínima expresión los derechos del inmigrante habilitando la detención sin orden judicial, así como los allanamientos de hogares donde hubiese sospecha de que se encontrasen inmigrantes irregulares y obligó a denunciar a los extranjeros sin documentación requerida para vivir en el país (MÁRMORA, 2004; NICOLAO, 2008).

La Ley Videla - no solamente restrictiva con respecto al fomento de la inmigración, sino opuesta a los derechos humanos - se mantuvo en democracia hasta el año 2003, momento en que se sancionó una ley progresista que otorgó a los extranjeros los derechos antes negados y facilitó la regularización de la situación migratoria de quien hubiese ingresado de manera ilegal en el país. En efecto, la Ley de Migraciones 25.871 (Ley Giustiniani $^{5}$ ) reconoció la migración como un derecho y estableció su garantía por parte del Estado. Asímismo, aseguró para todos los inmigrantes - sin importar su condición de regularidad - los derechos civiles y sociales (educación, salud, igualdad de derechos para los servicios sociales y derecho a un proceso en situación de detención) (GIUSTINIANI, 2004).

Con respecto a los discursos políticos y mediáticos, varios estudios parten de la sociología y de las ciencias de la comunicación para analizar el discurso sobre la inmigración durante los gobiernos de Carlos Menem (1989-1995 y 1995-1999). En estos estudios, se postula que los políticos y los medios de comunicación asociaban a los inmigrantes a la criminalidad y a la falta de trabajo en un contexto de crisis económica (MELELLA, 2015; COURTIS; LONGO, 2000; NOVICK, OTEIZA, 2000). Es decir, los extranjeros funcionaban como chivo expiatorio para los diversos problemas económicos y sociales que afrontaba el país.

5. Legislador socialista que propulsó la creación de la ley sancionada en el año 2003. 
Por su parte, los estudios desde una perspectiva íntegramente discursiva son escasos. Van Dijk (2003: 114-115) plantea que la escasez de análisis sistemáticos en América Latina desde el punto de vista de los estudios del discurso es el resultado de la negación de la existencia de prácticas y discursos racistas en la región.

El presente trabajo se inscribe en una investigación que analiza las representaciones construidas alrededor de los inmigrantes en el discurso político y legislativo argentinos entre el año 2003 y el 2018 con el objetivo de reconstruir el discurso dominante sobre la inmigración en dicho período. En esta ocasión en particular, nos proponemos analizar el tratamiento que se realiza sobre los inmigrantes en el discurso político en una coyuntura particular: la toma del Parque Indoamericano en el año 2010. Para eso, analizaremos discursos públicos del entonces jefe del gobierno, Mauricio Macri ${ }^{6}$, y de la entonces presidenta, Cristina Fernández ${ }^{7}$.

Nuestra hipótesis de trabajo es que, a pesar de pertenecer a dos partidos políticos diferentes con dos posturas públicas distintas frente a la inmigración, tanto Macri como Fernández reproducen las mismas representaciones presentes en el sentido común de la sociedad y, de esta manera, refuerzan el discurso dominante. Si esta hipótesis se comprueba, significaría que incluso para sostener actitudes y medidas políticas diferentes con respecto a la inmigración, las representaciones prejuiciosas presentes en el sentido común en Argentina en referencia a los extranjeros podrían encontrarse de forma subyacente. De esta manera, aunque las decisiones políticas no sean similares, se continuarían reproduciendo y fortaleciendo representaciones estereotipadas y xenófobas (AMOSSY; HERSCHBERG-PIERROT, 2001).

6. Miembro de la oligarquía argentina, líder del partido Propuesta Republicana y, a partir de diciembre de 2015, presidente de la Nación.

7. Miembro del Partido Justicialista, su proyecto político se acerca a un populismo de centroizquierda moderado. Durante su gobierno, se reglamentó la Ley Giustiniani y se procedió a la regularización de la situación de miles de inmigrantes a través de un programa denominado "Patria Grande". 


\section{Marco teórico}

Definimos "sentido común" como el conjunto de representaciones sociales compartidas por una comunidad (RAITER, 2003: 105). Los estímulos lingüísticos escuchados en el seno de una comunidad provocan en el sistema individual de creencias la construcción de una representación. Las representaciones se van acumulando y jerarquizando, de modo de tal que pasan a constituir el contenido del sistema de creencias de una persona. El conjunto de los contenidos de los sistemas de creencias individuales conforma el contenido del sentido común de la comunidad. Sin embargo, al mismo tiempo, el sentido común, en la medida en que se expresa por medio de enunciados, condiciona los contenidos posibles - o al menos verosímiles e incorporables - en los sistemas de creencias individuales. En este sentido, observamos una relación de interdependencia recíproca entre los sistemas de creencias particulares y el sentido común.

El sentido común está constituido por representaciones recibidas e incorporadas de manera no crítica tanto en la niñez, durante la socialización, como cuando somos adultos y procesamos lo que leemos o escuchamos de manera automática. Las representaciones son transmitidas de generación en generación básicamente por medio del lenguaje. Como los contenidos transmitidos por el lenguaje son tomados por verdaderos y, además, son recibidos de actores sociales con un determinado prestigio (padres, maestros, periodistas, etc.) de un modo - como dijimos - no crítico, las representaciones a las que estos estímulos obligan se incorporan como verdaderas sin ninguna fundamentación. Por lo tanto, son conocimientos que damos por sentado y son muy difíciles de refutar.

El sentido común es la totalidad de creencias compartidas por una comunidad, salvo por la existencia de variaciones individuales en el almacenamiento o conexión de las creencias ${ }^{8}$. El sentido común constituye, por lo tanto, un repertorio desordenado de representaciones que todos los integrantes de esa comunidad poseen. En cambio, el discurso dominante (RAITER; ZULLO, 2008) es un eje sociodiscursivo

8. Estas representaciones no necesitan ser idénticas para todos los miembros de la comunidad; es decir que no es la sumatoria de los sistemas de creencias individuales, sino una resultante. 
de referencias que determina qué representaciones del sentido común tienen más o menos circulación y son más o menos aceptadas. El discurso dominante califica todos los signos que circulan en una sociedad y establece grados de posibilidad, aceptación, verosimilitud, etc. Activar una determinada representación contenida dentro del sentido común, aunque sea para refutarla ("discurso opositor", en términos de Raiter y Zullo, 2008), contribuye a aumentar su circulación (LAKOFF, 2002 ; 2010) y, por lo tanto, a colocarla en un lugar privilegiado dentro del sistema de referencias que constituye el discurso dominante. Un ejemplo a nivel mundial es la frecuente asociación entre musulmanes y terrorismo: cada vez que se realice dicha asociación - sea para afirmarla o para refutarla - se activará en la mente de los hablantes dicha imagen mental o representación.

A diferencia de Raiter (2003), consideramos que el discurso dominante, antes que como un eje de referencias más o menos posibles y/o aceptables, puede ser mejor comprendido en términos de relaciones entre nodos de una red:

Thus, we may represent a belief as a collection of nodes related by paths or more specifically as graphs with edges and nodes, and so on. The node 'genocide' may thus be connected with the node 'Bosnia', whereas the latter node may again be related to the nodes 'country', 'ex-Yugoslavia' and 'Muslims', whereas the node 'genocide' may be related to such nodes as, 'mass killing', 'innocent people', 'holocaust', 'ethnic groups' or 'ethnic cleansing'. Such representations of beliefs in terms of graphs, or further 'clown' as neural networks, show more clearly than propositions that the content of a belief may be complex, and that beliefs may be related to many other beliefs (such as, 'Bosnia is a country in former Yugoslavia', etc.) (VAN DIJK 1998: 23).

Pensar las representaciones sociales como una red permite mostrar las relaciones y asociaciones entre diferentes conceptos. Además, permite comprender que ciertas conexiones pueden tener peso o fuerza distinta dentro del sentido común de una comunidad según, por ejemplo, cuán seguido se active o utilice dicha conexión. Así cada representación puede ser definida según el complejo estado de relaciones que presenta. 
Utilicemos un ejemplo de la actualidad política argentina. El signo Fondo Monetario Internacional (FMI), aunque formaba parte del sentido común de los argentinos, no estaba activo hasta mayo de 2018, cuando el presidente Mauricio Macri anunció la posibilidad de un acuerdo con dicho organismo como una salida positiva para la economía argentina. Sin embargo, la mayoría de los medios de comunicación y los políticos opositores asociaron FMI con otros signos, entre ellos: Riesgo País, default, endeudamiento, corralito ${ }^{9}$, crisis, hambre, cacerolazo ${ }^{10}$, trueque ${ }^{11}$, etc., que a su vez remitieron a la gran crisis político-económica que Argentina había vivido en el año 2001 y que había terminado con la renuncia del entonces presidente Fernando de la Rúa.

Entendiendo que las representaciones sociales que forman parte del sentido común de una sociedad constituyen una red de conceptos relacionados con diferente intensidad y dado que las nuevas representaciones se forman de un modo cohesivo con las preexistentes (RAITER, 2003), podemos observar de qué manera cada político clasifica a los inmigrantes y con qué otros marcos conceptuales los conecta.

En efecto, según la teoría de Framing, cada vez que utilizamos el lenguaje para hablar de algo, activamos marcos conceptuales en asociación con ese tema; eso se realiza de manera automática, así que no es algo que podamos evitar. Como los marcos se organizan en sistemas, una sola palabra no solamente activa su marco, sino también gran parte del sistema en el que se encuentra. Por ejemplo, la palabra "dinero" se encuentra asociada con un sistema de conceptos: ganar dinero, perder dinero, prestar dinero, banco, inversión, entre otras. Cuando hablamos del tiempo en términos de dinero, estamos activando, al menos, una parte de dicho sistema.

9. Así se llamó a la restricción de la libre disposición de dinero en efectivo proveniente de plazos fijos, cuentas corrientes y cajas de ahorros impuesta por el gobierno de Fernando de la Rúa a fines del año 2001.

10. Si bien hubo cacerolazos en otros momentos de la historia argentina, se trata de una forma de protesta encabezada mayormente por la clase media que se popularizó a fines del año 2001 y consistía en salir a las calles a golpear cacerolas u otros objetos similares. 11. Durante la crisis del año 2001, la población debió recurrir a clubs de trueque para poder satisfacer sus necesidades básicas de alimentos, ropa, higiene, etc. 
Cada vez que un marco conceptual se utiliza para hablar de un tema en particular - en nuestro ejemplo, del tiempo como dinero -, la asociación entre ese tema y ese marco se fortalece. Según Lakoff (2010:72), las posibilidades de cambiar los marcos con los que pensamos o nos referimos a un tema en particular son limitadas. Introducir una nueva manera de hablar requiere que sea comprensible para los interlocutores $\mathrm{y}$, para ello, debe tener sentido en términos del sistema existente de marcos. Además, es necesaria una difusión suficiente entre la población, suficientes repetición y confianza en los mensajeros para que el nuevo marco sea aceptado y consolidado. Por último, según esta propuesta, activar un marco para negarlo solo sirve para reforzar la asociación de ese marco con un determinado tema.

En términos de Lakoff (2007: 28), si se quiere modificar la valoración de un signo o las creencias de los hablantes vinculadas con un determinado tema, negar las valoraciones ya existentes es contraproducente. Es necesario proponer nuevos marcos conceptuales a partir de los cuales comenzar a comprender el fenómeno en cuestión. En este trabajo, utilizaremos la propuesta de Lakoff para determinar qué marcos conceptuales utilizan Macri y Fernández para hablar de los inmigrantes. Proponemos que, si bien ambos políticos valoran a los extranjeros de maneras diferentes y plantean distintas actitudes hacia ellos, en ambos casos se activan las mismas conexiones entre la inmigración y otros conceptos.

\section{La coyuntura: toma del Parque Indoamericano}

En diciembre del año 2010, un grupo de personas ocupó el Parque Indoamericano, ubicado al sur de la Ciudad de Buenos Aires, en reclamo por la falta de un proyecto de construcción de viviendas y entrega de terrenos (ZUKERFELD, 2013). La Policía Federal, junto con la Policía de la Ciudad de Buenos Aires, entonces llamada "Metropolitana", desarrolló un operativo conjunto de desalojo en el que fallecieron dos personas. El gobierno nacional comenzó una investigación por los dos asesinatos y pasó a disponibilidad a dos oficiales jefes y a tres suboficiales de la Policía Federal que participaron en el operativo. 
Vecinos de la zona, junto con habitantes de otros lugares, volvieron a instalarse en el parque en el día siguiente. Sin embargo, esta vez, formaron un cuerpo de delegados para diagramar un registro de quiénes eran efectivamente de la zona y tenían necesidad habitacional. Frente a la ausencia de efectivos policiales, otros vecinos decidieron liberar el parque por cuenta propia $y$, tras un enfrentamiento con los ocupantes, falleció una tercera persona. El entonces jefe de gobierno de la Ciudad de Buenos Aires, Mauricio Macri, le había solicitado a la presidenta de la Nación, Cristina Fernández, la presencia de la Policía Federal, pero el gobierno nacional consideró que la competencia judicial correspondía al gobierno local.

En este trabajo, analizamos la conferencia de prensa que brindó Mauricio Macri el 9 de diciembre de 2010 por el conflicto del Parque Indoamericano y un discurso de Cristina Fernández del 10 de diciembre de 2010 por ocasión del Día Universal de los Derechos Humanos. Se trata de dos discursos públicos de políticos de partidos enfrentados que se refieren a los disturbios mencionados.

\section{Análisis del corpus}

\subsection{Discurso de Mauricio Macri}

El 9 de diciembre de 2010, el jefe de gobierno de la Ciudad de Buenos Aires brinda una conferencia de prensa a la raíz del conflicto en el Parque Indoamericano. Entre otras cuestiones, determina su postura con respecto a los asesinatos ocurridos - fueron "con armas de tumberos"12, no de la policía - y pide al gobierno nacional que envíe a la Policía Federal para desalojar a los ocupantes del parque. Además, asocia los disturbios con la llegada de extranjeros a la ciudad de Buenos Aires.

Un primer elemento para destacar del discurso de Macri, hijo de un inmigrante italiano, es que realiza la estrategia de separación entre nosotros, los argentinos vs. ellos, los extranjeros (VAN DIJK, 2007: 11). En este sentido, no hay lugar en su conferencia de prensa para

12. Armas que se construyen dentro de las cárceles. 
considerar que los actuales ciudadanos argentinos también provienen, en buena medida, de la inmigración o que los inmigrantes son parte del nosotros que habita la ciudad de Buenos Aires:

1. Creo que los argentinos estamos abiertos a recibir gente honesta que quiera venir a trabajar a nuestro país.

El "nosotros" está dispuesto a recibir a "ellos" si cumplen un requisito que, al estar en modo subjuntivo, se aleja de la situación real ("quiera"). Junto con la utilización de un verbo de creencia y la expresión modal "estamos abiertos a", Mauricio Macri debilita el compromiso con sus dichos (HALLIDAY, MATHIESSEN, 2014; MARTIN, WHITE, 2005). El jefe de gobierno, en un caso hipotético, cree que estaría dispuesto, junto con su colectivo de identificación, a recibir inmigrantes, pero no es la situación de la que está hablando en su discurso. Esta distancia que pone Macri con respecto a sus dichos permite inferir al interlocutor que los inmigrantes de los que está hablando y a los que les adjudica la ocupación del Parque Indoamericano no serían gente honesta y no vendrían al país a trabajar.

Como mencionamos en la introducción de este artículo, los contenidos del sentido común reforzados por los políticos y los medios de comunicación ya en los años 90 asociaban a los inmigrantes con la inseguridad y la crisis económica (MELELLA ,2015; COURTIS, LONGO, 2000; NOVICK, OTEIZA, 2000) ${ }^{13}$. De esa manera, los inmigrantes eran conceptualizados como aquellos que les quitaban el trabajo a los argentinos y, por lo tanto, causaban la crisis de desempleo que vivía el país, sirviendo como chivo expiatorio para las políticas

13. A continuación, transcribimos solo algunos ejemplos provenientes de declaraciones de diferentes políticos y funcionarios públicos durante el año 1999 citados en Novick y Oteiza (2000): "Muchas veces llegan indocumentados y se organizan en bandas" (Carlos Menem, Presidente de la Nación); "si uno les pide a los indocumentados que se documenten, inmediatamente salta el tema de los derechos humanos. Derechos humanos sí, pero para todos, y no para proteger a los delincuentes, que se encuentran protegidos a partir de las leyes, que serán modificadas" (Carlos Menem, Presidente de la Nación); "[el Proyecto de Ley enviado al Congreso] castiga a quienes introducen a los inmigrantes indocumentados, es decir a las mafias que, además, los inician en el delito dándoles documentación falsa" (Carlos Corach, Ministro del Interior); "En la Capital Federal se extranjerizó el delito" (Hugo Franco, Director de Migraciones); "más del 60\% de los delitos menores como arrebatos y robos de pasacasete son cometidos por extranjeros"(Hugo Franco, Director de Migraciones). 
económicas neoliberales del gobierno nacional. Y, al mismo tiempo y paradójicamente, eran representados como aquellos que llegaban al país y, en lugar de trabajar honestamente, se dedicaban a delinquir. Es decir, se los culpaba de los hechos de inseguridad que experimentaban los ciudadanos.

Macri, en la conferencia de prensa del 9 de diciembre de 2010, activa uno de estos dos marcos conceptuales, aquel que asocia a los inmigrantes con el crimen (como vimos, el otro lo descarta, porque los inmigrantes de los que él habla no vienen a trabajar ni a quitar puestos de trabajo a los locales).

De acuerdo con nuestro análisis, el jefe de gobierno clasifica a los actores sociales que participaron del conflicto en tres categorías:

1) "La gente", que son los buenos vecinos que no infringen la ley y reclaman que las fuerzas de seguridad desalojen el espacio público ("la gente está reclamando porque cuidemos lo que es de todos, que pongamos límites al avance de esa delincuencia”);

2) Otro grupo también denominado "la gente", que no serían criminales, pero negocian con criminales ("Y le pido a toda la gente en buena fe, que vemos que están negociando con esos grupos de mafiosos y comprando un terreno, que no lo compre");

3) "Los delincuentes", que son los verdaderos responsables por la ocupación del parque y también son denominados como "grupo de mafiosos" aunque se aclara que son "unos pocos".

Los inmigrantes son asociados con los dos últimos grupos, los delincuentes y quienes negocian con los delincuentes.

El marco conceptual de la delincuencia se activa al asociar a los extranjeros con los siguientes sintagmas: "grupo de mafiosos", "delincuencia", "narcotráfico", "loteo del espacio público", "armas", "armas de tumberos", "dos muertes", "un país donde la droga estaba de paso a un país donde existen ya hoy muchos laboratorios", “inseguridad", "inmigración ilegal”, "armas ilegales", "usurpación”.

La inmigración es asociada, en el discurso de Mauricio Macri, con un segundo marco conceptual: el de las epidemias. La inmigración 
comparte con las epidemias dos características fundamentales de su definición, está fuera de control y toda la población se halla expuesta a ella:

1. No podemos seguir tan expuestos como sociedad insisto a una inmigración descontrolada.

2. La Argentina viene expuesta a una política inmigratoria descontrolada.

3. Convivimos con una situación descontrolada (todas las cursivas son nuestras).

Por último, el tercer marco conceptual que activa el discurso del jefe de gobierno conceptualiza a los inmigrantes como invasores. Esto se ve tanto en la repetición de la representación del "avance" y la ocupación que realizan los extranjeros, como también en la necesidad de defensa que plantea Macri:

4. El avance del narcotráfico, al avance de la delincuencia y que tenemos que defender la ley.

5. Seguimos trabajando para revertir la situación en el parque Indoamericano y para que se recupere ese espacio público que es de todos.

6. Pongamos límites al avance de esa delincuencia.

7. Donde todos los dias llegan cien, doscientas personas nuevas a la Ciudad de Buenos Aires, que no sabemos quiénes son, porque llegan de esta manera irregular.

8. El avance de la delincuencia y el narcotráfico en varios sectores de la Ciudad de Buenos Aires que todavía estamos a tiempo de revertir.

9. Todo este avance de inmigración ilegal.

10. Todo este avance de la usurpación tiene que ver con la inseguridad en la Ciudad de Buenos Aires (todas las cursivas son nuestras). 
En resumen, observamos que el jefe de gobierno activa representaciones sociales que ya estaban presentes en el sentido común, que vincula a los inmigrantes con la inseguridad que sufren los argentinos, y los enmarca en tres marcos conceptuales negativos (delincuencia, epidemia e invasión) que permiten llegar a la misma conclusión: los inmigrantes son una amenaza para los vecinos porque están fuera de control, siguen avanzando y porque son delincuentes asociados al narcotráfico.

\subsection{Discurso de Cristina Fernández}

Fernández pronuncia su discurso un día después de la conferencia de Macri en el marco de un acto por el Día Universal de los Derechos Humanos, en el cual la mandataria anuncia la creación del Ministerio de Seguridad. Si bien Fernández no nombra de manera explícita al jefe de gobierno, entabla con él una polémica al referirse al conflicto del Parque Indoamericano, a la represión llevada a cabo en ese lugar, a un intento de criminalización de los extranjeros y a ciertos dichos xenófobos de los últimos días.

En primer lugar, la presidenta intenta reducir la separación entre nosotros y ellos marcada por Macri. Fernández no considera que la ocupación del Parque Indoamericano esté relacionada con la presencia de ellos, los inmigrantes, sino que la postula como una cuestión "entre los argentinos":

11. Frente a cuestiones sociales, inclusive aquellas cuestiones sociales que también admitimos pueden estar siendo manipuladas interesadamente por alguien, exige - por parte de quienes tenemos la responsabilidad de conducir el Estado - un equilibrio, una paciencia y una articulación que impida generar o incitar más violencia o más enfrentamiento entre los argentinos (cursivas nuestras).

También rechaza la división entre nosotros y ellos al definirse como hija de inmigrantes (aunque de una manera un poco confusa) y argumentar que Argentina se constituyó a través de diferentes oleadas de inmigración: 
12. Yo vengo de una provincia. Primero que somos hijos de inmigrantes porque no soy descendiente de Luis XIV. No descendí de Luis XIV. Mis abuelos, como los abuelos o los padres de otros españoles, italianos y de tantas nacionalidades, bajaron de los barcos muertos de hambre aquí en la Argentina para venir a hacerse un hogar, también [venir] en lo que podríamos denominar "la última ola de inmigración", que es de la Patria Grande Latinoamericana, chilenos, uruguayos, bolivianos, paraguayos. Vengo de una provincia y de una familia. Ustedes saben, la madre de Néstor es chilena y allá en Río Gallegos y en Santa Cruz, la inmigración chilena primero, pero hoy en Caleta Olivia, en Puerto Deseado, en Río Gallegos, en Calafate, [hay] comunidades importantes de ciudadanos bolivianos, paraguayos.

En esta línea, categoriza los dichos del jefe de gobierno, aunque no lo nombre de manera explícita, como un caso de xenofobia:

13. Y yo sostengo - queridos compatriotas ${ }^{14}$ - que la xenofobia y el incentivar discriminaciones étnicas, religiosas o de cualquier naturaleza solo ha servido para que la humanidad protagonice sus capítulos y sus historias más negras y fatales.

En segundo lugar, Fernández rechaza el marco conceptual que vincula a los inmigrantes con la delincuencia y la inseguridad. La negación explícita implica ("no es través del miedo", "no es a través de enfrentar comunidades", "no estigmatizar") que otro actor social sí produce miedo, sí enfrenta comunidades, sí estigmatiza:

14. Pero no es a través del miedo, no es a través de enfrentar comunidades, que vamos a lograr seguridad.

15. Esto nos obliga a ser prudentes, a ser reflexivos, a no estigmatizar. Gente mala o que delinque, la hay de todas las nacionalidades, de todos los colores y de todas las religiones.

14. Sin embargo, se lo dice a sus "compatriotas", incluso ya habiendo explicitado que hay personas de otros países en el auditorio. Más adelante, les pide disculpas a los extranjeros por los dichos de Macri: "Y también, en nombre de todos los argentinos, aquí en este Salón de los Patriotas, pedir disculpas a algún país hermano si se ha sentido ofendido". 


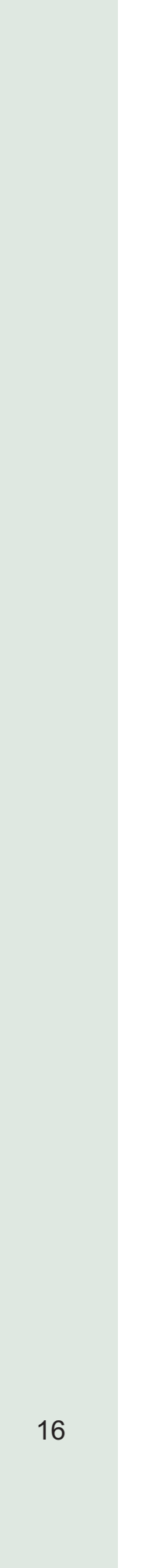

En tercer lugar, Fernández, para negar el carácter delincuencial de los inmigrantes, reafirma el laboral. Sin embargo, esto activaría un marco conceptual muy presente en el sentido común, aunque no haya sido mencionado: la responsabilidad de los inmigrantes en el desempleo de los argentinos. Para evitar la asociación de los inmigrantes tanto con la delincuencia como con el desempleo, la presidenta argumenta que los inmigrantes sí toman trabajos (no son delincuentes, sino personas laboriosas como las que Macri hubiera aceptado), pero no compiten con los locales en el mercado laboral, porque realizan aquellos trabajos que los argentinos no quieren realizar. De esta manera, se podría llegar a la conclusión de que el extranjero no solo no es un problema, sino que es útil y necesario para el funcionamiento de la economía argentina, siempre y cuando ocupe el rol que se le tiene asignado dentro de un determinado ordenamiento y distribución de tareas:

16. Por ejemplo, en Calafate, los ciudadanos bolivianos trabajan laboriosa y honradamente prácticamente todos en la industria de la construcción, como es en muchas partes.

17. Muchas de las verduras y de las frutillas que comemos todos los días, las cultivan ellos en el Suroeste de la provincia de Buenos Aires.

18. Yo, por lo pronto, en mi casa de Calafate tengo a María y a Ramón, dos maravillosos chilenos que cuidan hace años y quién no le fue alguna vez un albañil paraguayo o boliviano a arreglarle su casa, quién no tiene un encargado de edificio uruguayo.

19. Y por qué no decirlo, aquí en la Argentina, como en otras partes del mundo, los inmigrantes hacen las tareas y los trabajos que muchas veces los propios nacionales, porque han tenido mejor calidad de vida y mejores oportunidades, no hacen.

Consideramos que el discurso de Cristina Fernández posee una valoración sobre la inmigración diferente al de Mauricio Macri. No solo la inmigración no es una amenaza (rechaza el marco conceptual de la delincuencia), sino que es necesaria y positiva para el país: los inmigrantes realizan aquellos trabajos que los argentinos necesitan 
para mantener su forma de vida, pero no están dispuestos a realizar ellos mismos.

Sin embargo, al colocarse en el lugar de respuesta a la postura de Macri, refuerza las mismas representaciones presentes en el sentido común. La explicación, según la teoría de Lakoff, es que, al rechazar los marcos conceptuales que asocian la inmigración con la delincuencia y el desempleo, los está, de hecho, activando en las mentes de sus interlocutores. Al utilizar las asociaciones entre inmigración, inseguridad y delincuencia, las legitima y refuerza (LAKOFF, 2002). Así, no logra establecer una forma diferente de pensar o hablar sobre la inmigración, por ejemplo, conceptualizándola como un derecho humano o negando la relevancia de la nacionalidad.

Por otro lado, si bien intenta borrar la separación nosotros y ellos, no logra hacerlo y representa a los inmigrantes en ciertos estereotipos laborales que también forman parte del sentido común en Argentina (uruguayo $=$ portero, paraguayo $=$ albañil, etc.) y como posesiones valiosas de los argentinos ("en mi casa...tengo", "comemos...cultivan ellos"). De esta manera, los inmigrantes no son delincuentes, pero son personas asociadas con trabajos poco calificados e indeseables. En última instancia, la defensa de la inmigración se basa en una cuestión utilitaria, que beneficia a los argentinos y, por lo tanto, retoma de manera implícita la diferencia entre nosotros/ellos que niega de manera explícita.

\section{Consideraciones finales}

El presente trabajo constituye una primera etapa dentro de un proyecto de análisis del discurso político y legislativo sobre la inmigración en Argentina entre los años 2003 y 2018. El objetivo es problematizar las representaciones que se construyen sobre los extranjeros, determinar con qué marcos conceptuales se los asocia y confirmar si los marcos utilizados refuerzan el sentido común sobre los inmigrantes o si establecen una forma diferente de referirse a dichos actores sociales. 


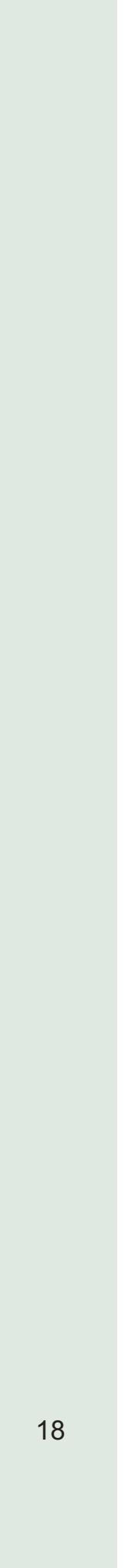

En esta ocasión, tomamos una coyuntura particular: la ocupación, en diciembre de 2010, del Parque Indoamericano por parte de habitantes de la Ciudad de Buenos Aires que exigían lugares donde vivir. Para su análisis, seleccionamos un discurso público del jefe de gobierno de la Ciudad de Buenos Aires, Mauricio Macri, y uno de la presidenta de la Nación, Cristina Fernández.

Observamos que ambos discursos valoran de manera diferente a los inmigrantes. En el caso de Mauricio Macri, la conclusión a la que el interlocutor debe llegar es que los extranjeros que residen en el país representan una amenaza y, en el caso de Cristina Fernández, la conclusión es que son beneficiosos para los argentinos. Sin embargo, ninguno de los dos sale del sentido común sobre la inmigración, plantea nuevas redes de conceptos para pensar o entender la problemática, ni reflexiona sobre las causas políticas y económicas detrás de este fenómeno poblacional.

Ambos políticos utilizan caracterizaciones de los inmigrantes basadas en el sentido común, que marcan una frontera entre "nosotros, los argentinos" y "ellos, los extranjeros". En el discurso del jefe de gobierno, la distinción nosotros/ellos se refleja en la diferencia entre personas que trabajan y personas que no trabajan y delinquen; mientras que en el de la presidenta la distinción nosotros/ellos descansa en el tipo de trabajo que realiza cada uno, dejando para los inmigrantes los trabajos poco calificados e indeseables. Además, ambos políticos utilizan marcos conceptuales relacionados con el peligro, aunque en el caso de Mauricio Macri sea para defenderlos y en el caso de Cristina Fernández para discutirlos.

Recordemos que la activación de un determinado marco conceptual, aunque sea para refutarlo, no hace otra cosa que (re)activarlo en el sistema de creencias de los interlocutores de ese discurso. En el caso de Mauricio Macri y Cristina Fernández, debido a sus roles políticos, sus discursos tienen una amplia llegada, son repetidos por los medios de comunicación masiva y poseen, al menos para un sector del electorado, el prestigio necesario para que las personas incorporen de una manera no crítica las representaciones de dichos discursos a sus sistemas de creencias. 


\section{Referencias}

ALVITES BAIADERA. 2012. Angélica. Estado y migración. Discursos sobre políticas migratorias. In: Actas de las VII Jornadas de Sociología de la Universidad Nacional de La Plata. La Plata: UNLP.

AMOSSY, Ruth; HERSCHBERG-PIERROT, Anne. 2001. Estereotipos $y$ Clichés. Buenos Aires: Eudeba.

BRUNO, Sebastián. 2007. Cifras imaginarias de la inmigración limítrofe en la argentina. Actas de las VII Jornadas de Sociología. Buenos Aires: Facultad de ciencias sociales, UBA.

CASTIGLIONE, Celeste. 2011. La gota que horada la piedra: Los migrantes en la prensa escrita argentina (1999-2007). Saarbrücken: Editorial Académica Española.

COURTIS, Corina; LONGO ELIA, Fernanda. 2000. La prensa como escenario del debate inmigratorio. Recuperado de: www.eca.usp.br.

GRIMSON, Alejandro. 1999. Relatos de la diferencia y la igualdad. Los bolivianos en Buenos Aires. Buenos Aires: Eudeba.

GRIMSON, Alejandro. 2006. Nuevas xenofobias, nuevas políticas étnicas en la Argentina. In: GRIMSON, Alejandro; JELIN, Elizabeth (Comps.). Migraciones regionales hacia la Argentina. Diferencia, desigualdad y derechos. Buenos Aires: Prometeo.

HALLIDAY, Michael; MATTHIESSEN, Christian. 2014. Halliday's Introduction to Functional Grammar. Londres y New York: Routledge.

LAKOFF, George. 1987. Women, Fire and Dangerous Things. Chicago/ London: University of Chicago Press.

LAKOFF, George. 2002. Moral Politics. How Liberals and Conservatives Think. Chicago and London: The University of Chicago Press.

LAKOFF, George. 2007. No pienses en un elefante. Lenguaje y debate político. Madrid: Editorial Complutense.

LAKOFF, George. 2010. Why it Matters How We Frame the Environment. Environmental Communication, 4(1): 70-81.

MÁRMORA, Lelio. 2004. Las leyes de migración como contexto normativo. In: GIUSTINIANI, Rubén (Comp.). Migración: un derecho humano. Buenos Aires: Prometeo.

MARTIN, James; WHITE, Peter. 2005. The language of evaluation. Appraisal in English. New York: Palgrave Macmillan.

MELLELA, Cecilia. 2015. Migraciones latinoamericanas y prensa gráfica. Análisis comparativo entre Argentina y España. Odisea. Revista de Estudios Migratorios, 2: 159-187.

NICOLAO, Julieta. 2008. Migración internacional y políticas migratorias. 

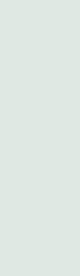

Estudio sobre las migraciones limitrofes hacia Argentina, y las políticas públicas implementadas por el gobierno de Néstor Kirchner (2003-2007). Tandil: Universidad Nacional del Centro de la Provincia de Buenos Aires.

NOVICK, Susana. 2008. Las migraciones en América Latina. Políticas, culturas y estrategias. Buenos Aires: Catálogos-Clacso.

NOVICK, Susana; OTEIZA, Enrique. 2000. Inmigración y derechos humanos. Política y discursos en el tramo final del menemismo. Buenos Aires: Instituto de Investigaciones Gino Germani, Facultad de Ciencias Sociales, Universidad de Buenos Aires.

OTEIZA, Enrique; NOVICK, Susana; ARUJ, Roberto. 1997. Inmigración y discriminación. Politicas y discursos. Buenos Aires: Grupo Editor Universitario.

RAITER, Alejandro. 2003. Lenguaje y sentido común. Las bases para la formación del discurso dominante. Buenos Aires: Biblos.

RAITER, Alejandro; ZULLO, Julia. 2008. Lingüistica y politica. Buenos Aires: Biblos.

TORRES, Victor. 2013. Cambios en la estructura sociodemográfica de los migrantes limítrofes de la última década en argentina. un aporte metodológico. Revista Astrolabio, 11: 311-333.

VAN DIJK, Teun. 1998. Ideology. A Multidisciplinary Approach. London: Sage

VAN DIJK, Teun. 2003. Dominación étnica y racismo discursivo en España y América Latina. Barcelona: Gedisa.

VAN DIJK, Teun. 2007. "Discurso Racista". In: IGARTUA, Juan José; MÚÑIZ Carlos (Eds.). Medios de comunicación y sociedad. Salamanca: Ediciones Universidad de Salamanca.

ZUKERFELD, Gilda. 2013. "Los participantes en el conflicto del parque Indoamericano". In: ZULLO, Julia (Ed.). Discurso, Identidad y Representación social. Mendoza: Editorial de la Facultad de Filosofía y Letras de la Universidad Nacional de Cuyo y Sociedad Argentina de Lingüística.

Recebido em: 16/07/2018

Aprovado em: 29/05/2019 